\title{
Introduction to the special issue in honor of Edward E. Smith
}

\author{
Jared X. Van Snellenberg • Deanna M. Barch
}

Published online: 30 January 2014

(C) Psychonomic Society, Inc. 2014

This special issue is dedicated to the life, work, and legacy of Edward E. Smith, PhD. Ed's career as a psychologist and cognitive neuroscientist was remarkable in virtually every respect: He had a tremendous impact on multiple areas of study, he received an impressive array of awards and honors, he mentored a number of students who have gone on to impressive careers of their own, and he was widely regarded by those who knew him as one of the kindest and most humble people that the field of psychology has ever known. Shortly after I (J.X.V.S.) first met Ed as a prospective graduate student at Columbia University in 2005, a faculty member at another school asked whom else I was considering working with. When I said Ed Smith, I received the reply "I can't say anything bad about Ed. He is probably the nicest man in psychology." Deanna first met Ed when he came to give a colloquium at Carnegie Mellon when she was a new postdoctoral fellow. He seemed more than happy to spend time with postdoctoral fellows and graduate students, was intellectually generous in his discussions, and insightfully shared his early experience in schizophrenia research, which presaged his later return to this field of study at the end of his career.

To attempt to list all of Ed's accomplishments, accolades, and influential articles would be a nearly Herculean task. An excellent summary of Ed's career can be found in the APS Observer article in his memory by his long-time colleague and collaborator Douglas L. Medin (2013), which also includes commentary (and some excellent anecdotes) from no fewer than 24 of his friends and colleagues. Suffice it to say that at

J. X. Van Snellenberg

Division of Cognitive Neuroscience, New York State Psychiatric Institute, New York, NY, USA

D. M. Barch $(\triangle)$

Departments of Psychology, Psychiatry and Radiology, Washington University in St. Louis, St Louis, MO, USA

e-mail: dbarch@artsci.wustl.edu the time of his death, Ed's curriculum vitae contained exactly 200 articles and chapters, many of which have been cited over 1,000 times, and that he continues to coauthor articles posthumously, as his collaborators complete the work that he was engaged in at the time of his death. It is particularly fitting that several of these projects are included in this volume.

One of the hallmarks of Ed's career was the tremendous impact that he had on multiple fields of study, and one of the major goals in putting together this volume has been to obtain submissions from Ed's collaborators, colleagues, and former students who have carried out work in each of these fields. The articles in this special issue generally fall into three broad categories that highlight the diversity of areas to which Ed made contributions: concepts and categories, working memory and cognitive control, and cognitive and rewardprocessing impairments in schizophrenia. Early in Ed's career, he focused on understanding how humans form concepts and on the structure of categorical knowledge representations, coauthoring many seminal studies in that field. The articles focused on concepts and categories in this special issue attest to the influence that his work had on the evolution of this domain of research.

Ed was also an early adopter of hemodynamic imaging techniques, first positron emission tomography, and later functional magnetic resonance imaging, because he recognized almost immediately that an understanding of how the human brain works could be used to adjudicate between competing theories of human cognition. As Ed often pointed out, no matter how appealing a theory of some aspect of human cognition was, it could only be taken seriously if it was consistent with the known functioning of the human brain. His application of these then-new imaging techniques to the study of working memory and cognitive control-and in particular, his work with his close colleague and friend John Jonides at the University of Michigan - quickly made him one of the preeminent experts on working memory. This was due 
in part to his ability to integrate sophisticated cognitive constructs with work on brain function to generate integrated theories that represented a deep bonding of psychological and neurobiological evidence. It was on the strength of this work, as well as due to his profound impact on the field of conceptual and categorical reasoning, that Ed was elected to the National Academy of Sciences of the USA in 1996.

Later in his career, Ed's work took on a new focus, although, as was noted above, it was a return to an early area of interest. When he moved from the University of Michigan to Columbia University in 2004, the psychiatry department at the Columbia University Medical Center immediately began trying to recruit Ed to become the Director of their Division of Cognitive Neuroscience and to study the cognitive deficits in schizophrenia. Ed accepted this position in 2008 , and it has no doubt been a great loss to our understanding of cognition in schizophrenia that Ed had only four years to pursue this work before he passed away. Fortunately, he began several studies during this time, some of which are appropriately being published in this volume, and some of which are still underway.

Ed was an intellectually and personally generative, kind, creative, and profoundly energetic scientist whose influences on multiple fields of research will no doubt stand the test of time. He is already sorely missed, but his many students, postdoctoral fellows, and collaborators are continuing the work that he helped to start, and the breadth and depth of these studies are hopefully well illustrated by the contributions to this special issue.

\section{Reference}

Medin, D. L. (2013). Remembering Edward E. Smith. APS Observer, 26(4). Retrieved from www.psychologicalscience.org/index.php/ publications/observer/2013/april-13/remembering-edward-e-smith2.html 